\title{
How Good Are Trade and Telephone Call Traffic in Bridging Income Gaps and TFP Gaps?*
}

\author{
Wei-Kang Wong
}

October 22, 2003

\begin{abstract}
This paper empirically evaluates the relative importance of embodied versus disembodied idea flows in explaining income gaps and total factor productivity (TFP) gaps. Trade is used as a measure of embodied idea flows and telephone call traffic a measure of disembodied flows. Since both trade and telephone traffic may be endogenous, this paper uses the geographic, linguistic, and colonial components of trade and telephone traffic as instruments to identify their effects on income and TFP. The results provide little support for the embodied object models when both trade and telephone traffic are included in the regressions. Telephone traffic has a quantitatively larger effect on income per worker and TFP than trade.
\end{abstract}

JEL: F43, O33, O40.

Keywords: Embodied and Disembodied Idea Flows, Telephone Traffic, Trade, Income Gaps, TFP Gaps.

\footnotetext{
*Wei-Kang Wong, Department of Economics, National University of Singapore, AS2, 1 Arts Link, Singapore 117570, Republic of Singapore; email: ecswong@nus.edu.sg; fax: (65) 6775-2646; tel: (65) 6874-6016. I especially thank Hélène Rey for sharing the data on telephone call traffic. This paper owes its existence to her generosity. I am extremely grateful to George Akerlof, David Romer, J. Brad De Long, and Richard Lyons for numerous comments and suggestions. I also thank Barry Eichengreen, James Powell, Chris Meissner, Julian di Giovanni, Philip Oreopoulos, participants at the Macroeconomics Seminar at UC Berkeley, and an anonymous referee for very helpful feedback; the IBER and the International Telecommunication Union for helps with the telephone traffic data. The usual disclaimer applies.
} 


\section{Introduction}

This paper is an empirical investigation of the relative importance of embodied versus disembodied idea flows in bridging income gaps - through total factor productivity (TFP) gaps and object gaps; ideas are "disembodied" if they are free from any connection with a piece of equipment. Conversely, ideas are "embodied" if their diffusion requires transfer of physical objects. Although the original 'embodiment' controversy between Solow (1960) and Jorgensen (1966) focused on whether disembodied ideas are free - in contrast to embodied ideas that entail costly investment this paper does not make this distinction. ${ }^{1}$ Both embodied and disembodied ideas may be costly. ${ }^{2}$

The TFP gap captures the idea gap. The distinction between "idea gap" and "object gap" in economic development was first made by Romer (1993). An idea gap arises because poor countries do not have access to ideas that are used in industrial nations to generate economic value, whereas an object gap is due to a lack of objects such as factories, roads, and raw materials.

It is useful to distinguish between embodied and disembodied idea flows and to disentangle their effects on income gaps and TFP gaps because they imply different mechanisms through which ideas are diffused. If the effects of embodied flows dominate, then investment and imports of machinery and equipment are necessary to bridge both idea gaps and object gaps. This in turns highlights the importance of savings and accumulation on economic development. On the other hand, if disembodied flows are more important, then more interaction and communication with developed countries are key. Different policy prescriptions are called for depending on which gap is perceived to be dominant and whether embodiment is a crucial feature of technological transfer. Economists disagree on the relative importance of idea gaps and object gaps in economic development. ${ }^{3}$ They also disagree on the relative contribution of embodied and disembodied idea flows in bridging these gaps. This is the issue this paper addresses.

Romer (1993) stresses the importance of embodied idea flows. A large literature, including De Long and Summers (1991), has come to regard technology embodied in machinery and equipment as "the lever of riches." ${ }^{4}$ The empirical

\footnotetext{
${ }^{1}$ See Hercowitz (1998).

${ }^{2}$ In reality, disembodied ideas need not be free if exclusion is possible. "Excludability," as Paul Romer explained, "is a function of both the technology and the legal system." (Romer 1990, S74.)

${ }^{3}$ For example, the new growth theory holds the view that the idea gap and its determinants are the more important element in explaining economic development.

${ }^{4}$ See Mokyr (1990).
} 
research in the literature thus far focuses exclusively on the significant positive contribution of "idea-embodying object flows," such as trade and foreign direct investment, in closing income gaps. ${ }^{5}$ Special types of object flows notwithstanding, it seems ironic that after downplaying the importance of object gaps, ultimately the new growth literature has to rely on object flows to close these idea gaps. More importantly, if disembodied idea flows turn out to be at least as important as embodied flows, then the exclusive emphasis on embodied flows in the existing literature would be misplaced.

This paper uses international telephone call traffic as a proxy for disembodied idea flows, and international trade as a proxy for embodied idea flows. Telephone call traffic and trade clearly fit my definition of embodiment: talking over the phone requires no transfer of physical objects, while trading generally does. Given that international telephone calls are costly, the economizing behavior of economic agents would suggest that such traffic should contain valuable information. For instance, Portes and Rey (2000) have found telephone call traffic to be an important associate of cross-country portfolio equity investment flows; it transmits information across national borders.

Admittedly, this choice of the two proxies is largely driven by data availability: the data for other examples of embodied and disembodied flows are simply not available for a large cross-section of countries. Thus, more generally, trade and telephone call traffic may be regarded as merely proxies, rather than taken literally. On the other hand, the similarities between telephone call traffic in my earlier sample period (1985) and internet traffic in the later period may allow us to use the findings to assess the likely impact of the internet on idea diffusion, as internet makes available large amount of information that are accessible for a small cost.

To identify their effects on income, both trade and telephone call traffic have to be instrumented because they may ${ }^{5}$ For example, Coe and Helpman (1995) and Coe, Helpman, and Hoffmaister (1997) single out international trade, particularly imports of machinery and equipment, as the main channel of R \& D spillovers. On the other hand, Borensztein, De Gregorio, and Lee (1998) emphasize the interaction between human capital in the host country and foreign direct investment (FDI) in determining the success of technology transfer. However, these papers fail to address the endogeneity of trade and FDI in a satisfactory way. Recognizing that trade may be endogenous, Frankel and Romer (1999) instrument it using geographic characteristics of the countries. They find no evidence that the OLS estimate of the effect of trade overstates the causal effect. In fact, their IV estimate is always larger than the OLS estimate, a finding they attribute to sampling error. 
be endogenous: countries whose incomes are high for reasons other than trade and telecommunication flows may have higher trade shares and telephone call traffic. There is also a concern about reverse causality: richer countries may simply trade more and demand more telecommunication, ceteris paribus. The instruments I use are measures of the geographic, linguistic, and colonial components of countries' trade and telephone call traffic abroad.

The geographic characteristics of a given country are exogenous. However, as the empirical analysis later reveals, the same geographic factors that explain trade also explain telephone call traffic. Thus in using geographic factors to estimate trade's effect on income, it is necessary to control for telephone call traffic to avoid omitted variable bias, and vice versa. As for linguistic and colonial factors, it is difficult to think of reasons that the match of two countries' linguistic and colonial profiles could have important effects on their income gaps except through their impact on trade and communication. In particular, learning about better institutions (Hall and Jones, 1999) and adoption of different legal systems (La Porta et al. 1999) can be regarded as special cases of disembodied idea flows. While the linguistic variable is crucial in obtaining good instruments for trade and telephone call traffic, the results turn out to be insensitive to the inclusion of colonial ties.

The instruments are constructed along the line of Frankel and Romer (1999): first, a bilateral trade equation and a bilateral telephone call traffic equation are estimated using bilateral geographic, linguistic, and colonial factors; next, the fitted values of the equations are aggregated to estimate the geographic, linguistic, and colonial components of countries' overall trade and telephone call traffic abroad. With these instruments, I can then distinguish the effects of embodied and disembodied idea flows on income: I estimate cross-country regressions of income per person on international trade, international telephone call traffic, and country size by instrumental variables. There are four main findings.

First, telephone call traffic has a quantitatively large, though only moderately statistically significant, positive effect on income. Second, inclusion of telephone call traffic with trade reduces the IV estimate on trade by about three quarters in the baseline regression. The estimates imply that a one standard deviation change in the logarithm of telephone call traffic per worker explains three times as much variation in the logarithm of income per worker as a one standard deviation change in trade share. Third, the estimates are sensitive to the inclusion of a latitude variable: the standard errors increase sharply, and none of the coefficient estimates remain statistically significant, either from zero or from the baseline estimates, at the conventional levels. Fourth, telephone call traffic bridges income gaps through 
idea gaps, rather than through object gaps. Thus, the evidence provides relatively little support for the embodied object models when both trade and telephone call traffic are included in the regressions. Disembodied idea flows emerge as the more important factor in bridging income gaps and idea gaps.

The remainder of this paper proceeds as follows. Section 2 discusses the basic framework and derives the estimating equation. Section 3 constructs the instruments for both trade and telephone call traffic. With these instruments, section 4 distinguishes the effects of trade and telephone call traffic on income, and checks for robustness. Section 5 then determines whether the effects work through idea gaps or object gaps. Section 6 concludes.

\section{The Basic Framework}

To distinguish the effects of trade and telephone call traffic on income, this paper adopts the basic framework of Frankel and Romer (1999). Frankel and Romer (1999) examine the causal effect of trade on income using instruments constructed from a gravity model based only on geographic factors. Their results suggest that trade has a quantitatively large and robust, though only moderately statistically significant, positive effect on income level. There are two reasons for adopting their setup. First, their paper is the most careful empirical analysis to date in controlling for possible endogeneity of trade. ${ }^{6}$ Second, it is straightforward to extend their framework to construct instruments for both trade and telephone call traffic. The basic setup consists of the following steps.

\section{A. The Income Equation}

First, the per capita income in country $i$ is postulated to be a function of economic interactions with the outside world ("international trade" and "international telephone call traffic"), economic interactions within the country ("within-country trade" and "within-country telephone call traffic"), and other factors.

$$
\begin{aligned}
\ln Y_{i}=\beta_{0}+ & \beta_{1} \text { Trade }_{\text {international }, i}+\beta_{2} \operatorname{lnTel}_{\text {international }, i} \\
& +\beta_{3} \text { Trade }_{\text {within }, i}+\beta_{4} \text { lnTel }_{\text {within }, i}+\epsilon_{i},
\end{aligned}
$$

${ }^{6}$ In addition, as argued by Rodriguez and Rodrik (2000), most of the other papers on trade and openness can be shown to be non-robust. Note, however, that Frankel and Romer's paper has not been completely exempted from criticisms. See, for example, Rodriguez and Rodrik (2000), pp54 - 56, for their comments on a particular robustness issue in Frankel and Romer (1999). 
where $Y_{i}$ is income per worker, Trade international, $i_{i}$ and Tel $_{\text {international }, i}$ are respectively international trade share and international telephone call traffic per worker, while $\operatorname{Trade}_{w i t h i n, i}$ and $T e l_{\text {within }, i}$ are respectively the withincountry trade and the within-country telephone call traffic. $\epsilon_{i}$ is the disturbance term.

\section{B. Within-Country Interactions}

Second, since the data on within-country trade and within-country telephone call traffic are unavailable, they are assumed to be functions of the country's size, measured by population and area. In other words, larger size provides greater scope for within-country interaction because there are more fellow citizens to interact with:

$$
\begin{aligned}
& \operatorname{Trade}_{\text {within }, i}=\beta_{0}+\beta_{1} \ln N_{i}+\beta_{2} \ln A_{i}+\omega_{i}, \\
& \operatorname{lnTel}_{\text {within }, i}=\gamma_{0}+\gamma_{1} \ln N_{i}+\gamma_{2} \ln A_{i}+\eta_{i},
\end{aligned}
$$

where $N_{i}$ is population and $A_{i}$ is area.

\section{The Estimating Equation}

Substituting equations (2) and (3) into the income equation (1), I can express income per worker as a function of international trade, international telephone call traffic, population and size. This yields the estimating equation:

$$
\ln Y_{i}=c_{0}+c_{1} \ln N_{i}+c_{2} \ln A_{i}+c_{3} \text { Trade }_{\text {international }, i}+c_{4} \ln \operatorname{Tel}_{\text {international }, i}+\varsigma_{i} .
$$

Equation (4) can be thought of as an extension of Kremer's (1993) model of endogenous technological change when idea diffusion is costly. Kremer (1993) postulates that a large population spurs technological change because it increases the number of potential inventors. However, even if technology is nonrival, as Kremer (1993) assumes, its diffusion may not be smooth and costless, due to barriers such as geographic and linguistic differences. If idea diffusion is costly, then the effective population for idea production for a country is neither limited to the size of its domestic population, nor is it fully augmented by the world population. Instead, the effective population for idea production for any country is its domestic population, augmented by its interactions with the rest of the world through embodied and disembodied idea flows, measured here by international trade and international telephone call traffic respectively. 


\section{The Instruments for Trade and Telephone Call Traffic}

\subsection{Constructing the Instruments}

Since both international trade and international telephone call traffic may be endogenous, they have to be instrumented. Frankel and Romer (1999) show that a country's geographic features, such as its size and its proximity to other countries, have important effects on its bilateral and overall trade. However, these geographic features should also be correlated with the volume of telephone call traffic among countries, as geography largely determines the ease of interaction among different regions through much of history. Thus, to use these variables as instruments to identify trade's effect on income, it is necessary to control for telephone call traffic, and vice versa; otherwise, the instruments constructed from these variables are invalid because they would be correlated with the omitted variable contained in the error term.

While geographic variables may adequately explain the pattern of trade, they may be insufficient to account for the pattern of telephone call traffic. After all, a common language is the prerequisite for verbal communication. Thus, the more likely that a randomly drawn person from one country speaks the same language as a randomly drawn person from another country, the higher the interactions between these two countries should be. Finally, colonial ties may also be relevant for the general pattern of interactions. To illustrate, consider the case of Singapore. Since Singapore was a colony of the United Kingdom, there should be more interactions between Singapore and the United Kingdom. However, this colonial tie should have no effect on Singapore's interactions with other countries, say the United States or Japan.

Equally important, it is hard to think of reasons that the match of two countries' geographic, linguistic, and colonial profiles could have important effects on income except through their effects on bilateral embodied and disembodied flows. Thus, these bilateral geographic, linguistic, and colonial variables can be used to obtain instrumental variables estimates of the impact of trade and telephone call traffic on income. To construct the instruments for trade and telephone call traffic, I adopt the two-stage framework used by Frankel and Romer (1999): first, bilateral geographic, linguistic, and colonial characteristics are used to predict bilateral trade shares and telephone call traffic per worker; next, the predicted values are aggregated over a country's trading or calling partners. The aggregated values are the instruments for the country's overall trade shares and telephone call traffic per worker. 


\section{The Bilateral Prediction Equations}

More concretely, in the first stage, the following bilateral regressions are estimated:

$$
\begin{aligned}
& \ln \operatorname{Trade}_{i j}=a_{0}+a_{1} \ln D_{i j}+a_{2} \ln N_{i}+a_{3} \ln A_{i}+a_{4} \ln N_{j}+a_{5} \ln A_{j}+a_{6}\left(L_{i}+L_{j}\right) \\
& +a_{7} B_{i j}+a_{8} B_{i j} \ln D_{i j}+a_{9} B_{i j} \ln N_{i}+a_{10} B_{i j} \ln A_{i}+a_{11} B_{i j} \ln N_{j} \\
& +a_{12} B_{i j} \ln A_{j}+a_{13} B_{i j}\left(L_{i}+L_{j}\right)+a_{14} L A N G U A G E_{i j} \\
& +a_{15} B R I T A I N_{i j}+a_{16} F R A N C E_{i j}+a_{17} S P A I N_{i j}+\mu_{i j} \\
& \operatorname{lnTel}_{i j}=b_{0}+b_{1} \ln D_{i j}+b_{2} \ln N_{i}+b_{3} \ln A_{i}+b_{4} \ln N_{j}+b_{5} \ln A_{j}+b_{6}\left(L_{i}+L_{j}\right) \\
& +b_{7} B_{i j}+b_{8} B_{i j} \ln D_{i j}+b_{9} B_{i j} \ln N_{i}+b_{10} B_{i j} \ln A_{i}+b_{11} B_{i j} \ln N_{j} \\
& +b_{12} B_{i j} \ln A_{j}+b_{13} B_{i j}\left(L_{i}+L_{j}\right)+b_{14} L A N G U A G E_{i j} \\
& +b_{15} B R I T A I N_{i j}+b_{16} F R A N C E_{i j}+b_{17} S P A I N_{i j}+\nu_{i j},
\end{aligned}
$$

where $i$ refers to the home country and $j$ denotes the partner country in trade or telephone calls. Trade $e_{i j}$ is the bilateral trade share between countries $i$ and $j$, measured as exports plus imports as a ratio of GDP in country $i$. Tel $l_{i j}$ is the outgoing telephone call traffic from country $i$ to country $j$, divided by the number of workers in country $i .^{7}$ The geographic variables are defined as follows: $D$ is distance, $N$ is population, $A$ is area, $L$ is a dummy for landlocked countries, $B$ indicates whether two countries share a common border.

$L A N G U A G E_{i j}$ is the linguistic variable. It measures the probability that a randomly drawn person from country $i$ speaks the same language as a randomly drawn person from country $j$. Specifically, let $p_{i, 1}, p_{i, 2}, \ldots, p_{i, 100}$ denote the proportion of people who speak each of the top 100 languages in country $i$. The probability that a randomly drawn person from country $i$ speaks the same language as a randomly drawn person from country $j$ is simply $L A N G U A G E_{i j}$ $=\sum_{k=1}^{100} p_{i, k} p_{j, k}$. There are four points to note about the linguistic variable.

First, only the first language or the mother tongue is considered. ${ }^{8}$ Second, only the one hundred most widely used

${ }^{7}$ I use only outgoing telephone call traffic because most of the data for incoming traffic are missing. However, this asymmetric treatment of trade and telephone traffic is unlikely to drive the results below as Frankel and Romer (1999) report that the gravity approach cannot separate the effects of imports and exports.

${ }^{8}$ Thus, I ignore the fact that some people may be fluent in more than one language. There are a few reasons for 
languages are considered. ${ }^{9}$ Third, unlike Hall and Jones (1999) who use only European languages as instruments, I include many languages that are widely used and originate from outside Europe. Using only European languages as instruments could incur a selection bias: European countries and countries that consist mainly of emigrants from Europe tend to have higher incomes per capita, perhaps for reasons unrelated to how linguistic profiles facilitate idea flows. Finally, my linguistic measure is not merely a country specific constant, but varies across country pairs $i$ and $j$.

BRITAIN, FRANCE, and SPAIN are the colonial dummies that capture the greater interactions between the ex-colonizers and their ex-colonies due to their colonial ties. Specifically, BRITAIN $N_{i j}$ equals one if the two countries $i$ and $j$ are the United Kingdom and one of its ex-colonies, and zero otherwise. FRANCE and SPAIN are similar dummies for France, Spain, and their ex-colonies.

\section{Data and Results}

The data on bilateral telephone call traffic come from International Telecommunication Union's (ITU) Direction of Traffic 1999. They are for 1985, and cover telephone call traffic between nearly 200 countries. There are many missing considering only the first language. First, the mother tongue of a person is more likely to be exogenous. On the other hand, the second or third language that a person chooses to learn could be endogenous, driven in particular by the expected economic gain from the command of such a language. Second, it is extremely hard to assess and measure a person's proficiency in the second or third language. Third, interaction and communication are most efficient in one's mother tongue. Fourth, including second or third languages in the probability calculation presents a data problem: conditional, rather than unconditional probabilities would have to be used.

${ }^{9}$ The practical difficulty of including all languages is apparent. There are thousands of living languages in use today. However, the error introduced by limiting the study to only the top one hundred languages is likely to be very small. The reason is that in considering the effect of a common language on international interactions, we are only interested in languages that are widely used. If a language is only used by a small group of people, or by people concentrated in a given country, it is unlikely to have any effect on cross-border interactions. The $100^{\text {th }}$ most commonly used language on our list is North Azerbaijani. It is used by about 7 million people worldwide. About 6 millions (86 percent) of the users reside in Azerbaijan alone. The second and third largest group of users of 336,000 (4.8 percent) and 308,000 (4.4 percent) reside in Russia and Georgia respectively. Thus, it is unlikely that any language below the top one hundred languages would have a significant effect on cross-border interactions. 
values. I use all available data to estimate the bilateral telephone call traffic equation. The data on total international telephone call traffic come from ITU's World Telecommunication Indicators 1995. The data consist of both incoming and outgoing telephone call traffic. However, I use only the outgoing traffic, as the data for most incoming traffic are unavailable.

The data on trade shares and geographic characteristics come from Frankel and Romer (1999). The data are for the year 1985. ${ }^{10}$ The linguistic variable is calculated using data from Ethnologue of the Summer Institute of Linguistics (SIL). Finally, the colonial dummies are compiled from The World Factbook of the Central Intelligence Agency (CIA). ${ }^{11}$

Table 1 reports the OLS estimates of the bilateral regressions, equations (5) and (6). Essentially all the coefficients have the expected signs. The determinants have very similar qualitative effects on both trade and telephone call traffic, except for some of the interaction terms, which are mostly not statistically significant. Specifically, bilateral trade and telephone call traffic are lower if two countries are further apart, if at least one of them are landlocked, or if their country sizes allow for more internal interactions relative to external ones. For example, simultaneous increases in population and area in the home country (country $i$ ) widen the scope of home-country interations relative to between-country interactions. On the contrary, simultaneous increases in population and area in the trading or calling partner (country j) improve the scope of between-country interactions relative to within-country interactions from the perspective of the home country. Thus, bilateral interactions between countries $i$ and $j$ are higher if the home country (country $i$ ) is ${ }^{10}$ There are some minor errors that have been corrected here. These errors have not affected their results in any substantial way. The errors are in their estimation sample. Their prediction sample is fine. Specifically, the common border variable was coded incorrectly between four pairs of countries (eight observations) in the estimation sample. They are (Switzerland, Norway), (Denmark, Sweden), (Spain, France), and (Norway, Sweden). In addition, the area variable for Saudi Arabia is coded differently in the estimation sample and the prediction sample. I have realigned it at the value used in the prediction sample, which is 865,000 square miles.

${ }^{11}$ See http://www.cia.gov/cia/publications/factbook/index.html for the online version. For countries that have been colonized by different countries, the ex-colonizer refers to the last of the colonizers. Some countries were placed under the care of a particular country under UN-trusteeship during the transition from colonization to independence. In that case, the caretaker country is taken to be the ex-colonizer here. 
smaller or if the partner country (country $j$ ) is larger. ${ }^{12}$

On the other hand, bilateral interactions are higher if two countries share a common border, a common language, or a colonial tie. For example, a one standard deviation increase in the probability of a common language would raise telephone call traffic per worker and trade share by 15.06 percent and 8.29 percent respectively, ceteris paribus. ${ }^{13}$ Similarly, telephone call traffic per worker and trade share between Britain and any of its ex-colonies are expected to be roughly 38 and 4 times higher than otherwise. ${ }^{14}$

It is worth emphasizing that all the variables in equations (5) and (6) - except population and area - are measured at the bilateral level, not the aggregate level. This is desirable because it is even less likely that these bilateral, countrypair specific characteristics would correlate with the aggregate error term $\epsilon_{i}$ in the income equation (4).

\section{The Aggregation Equations}

In the second stage, the fitted values from the bilateral trade and bilateral telephone call traffic equations are aggregated over each country's trading or calling partners to estimate the geographic-linguistic-colonial components of a country's international trade and telephone call traffic. First, rewrite equations (5) and (6) as

$$
\begin{aligned}
\operatorname{lnTrade}_{i j} & =a^{\prime} X_{i j}+\mu_{i j}, \\
\operatorname{lnTel} & =b^{\prime} X_{i j}+\nu_{i j},
\end{aligned}
$$

where $a$ and $b$ are the vectors of coefficients in the bilateral regressions (5) and (6) respectively, and $X_{i j}$ is the vector of geographic, linguistic, and colonial variables. The measures of the geographic-linguistic-colonial component of

\footnotetext{
${ }^{12}$ Recall that $T e l_{i j}$ and Trade $_{i j}$ are normalized with respect to the home country (country $i$ ). Moreover, following Frankel and Romer (1999), I consider the impact of an increase in population and area together, with no change in population density.

${ }^{13}$ This is calculated using the standard error of the probability of a common language in the full sample for which data is available; it is equal to 0.0891 for 30,102 pairs of countries. However, the standard error is larger in the sample used for estimation; it is equal to 0.1328 . Using the latter standard error, a one standard deviation increase in the probability of a common language would have raised bilateral telephone call traffic and trade share by $22.44 \%$ and $12.35 \%$ instead.

${ }^{14}$ They are calculated as $\left(e^{3.67}-1\right)$ and $\left(e^{1.59}-1\right)$ respectively.
} 
country $i$ 's total trade share and telephone call traffic per worker are then given by

$$
\begin{aligned}
& \text { Trade }_{\text {international }, i}=\sum_{j \neq i} e^{\hat{a}^{\prime} X_{i j}}, \\
& \text { Tel } \text { international, } i=\sum_{j \neq i} e^{\hat{b}^{\prime} X_{i j}},
\end{aligned}
$$

where $\hat{a}$ and $\hat{b}$ are the vectors of coefficient estimates reported in Table 1. Equations (9) and (10) predict the components of countries' bilateral trade and telephone call traffic that are attributable to geographic characteristics, linguistic profiles, and colonial history, and then aggregate these components over all of a country's trading or calling partners to obtain the exogenous components of countries' overall trade and telephone call traffic. These constructed variables

$\left(\right.$ Trade $_{\text {international }, i}$ and $\left.\ln T e l_{\text {international }, i}\right)$ are my instruments for the actual variables $\left(\right.$ Trade $_{\text {international }, i}$ and $\ln$ Tel $\left._{\text {international }, i}\right)$ in the estimating equation (4).

As Frankel and Romer (1999) point out, all that is needed to perform the calculations in equations (9) and (10) are countries' geographic, linguistic, and colonial characteristics. I therefore take the sum not just over the estimating sample, i.e., countries with data on bilateral trade and telephone call traffic, but over all countries in the world with data on the exogenous variables $X_{i j}$, including those with no data on bilateral trade or telephone call traffic.

\subsection{Testing the Quality of the Instruments}

This section tests the quality of the instruments constructed above. Frankel and Romer (1999) argue that the component of the constructed trade share that is correlated with country size cannot be used to estimate the effect of trade on income because it could be confounded by the within-country interactions: a large country size promotes withincountry interactions and discourages between-country interactions at the same time, as a larger country is likely to be farther away from the other countries. Thus, in using distance to construct instruments for between-country interactions, it is necessary to control for country size. Columns (1) and (2) in Table 2 estimate the first stage regressions to investigate whether the constructed variables provide information beyond that contained in country size. Figure 1 shows the partial correlation plot between actual and constructed trade shares, controlling for the country's area and population size. Figure 2 shows a smilar plot for actual and constructed telephone call traffic.

The results show that the geographic-linguistic-colonial model produces good instruments for both trade and telephone call traffic; the constructed variables do contain a considerable amount of information about the actual 
variables beyond that contained in country size.

\subsection{The Outliers}

Nevertheless, Figure 1 reveals two large outliers - Luxembourg and Singapore - in the relationship between actual and constructed trade share. They are the same outliers identified in Frankel and Romer (1999). To examine robustness, columns (3) and (4) in Table 2 re-estimate the first stage regressions, omitting these outliers. Figures 3 and 4 show the partial plots. The plots still show positive correlations between actual and constructed variables. Both partial correlations are still statistically significant at the 10 percent level. Thus, these correlations appear to be quite robust to the outliers.

\section{Trade or Telephone Call Traffic? Embodied Idea Flows Versus Disem- bodied Idea Flows}

With the instruments, I can distinguish the relative importance of trade and telephone call traffic - corresponding conceptually to embodied versus disembodied idea flows - in bridging income gaps. In other words, I examine whether technological spillover works by expanding the variety of goods available to the economy or by providing access to productive ideas generated elsewhere. 


\subsection{Basic Results}

To identify the effects of trade and telephone call traffic on incomes, I estimate equation (4), reproduced below, by in-

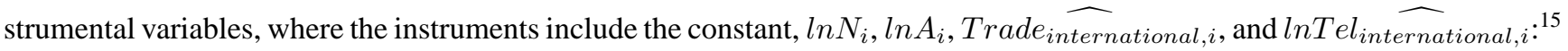

$$
\ln Y_{i}=c_{0}+c_{1} \ln N_{i}+c_{2} \ln A_{i}+c_{3} \text { Trade }_{\text {international }, i}+c_{4} \ln \operatorname{Tel}_{\text {international }, i}+\varsigma_{i}
$$

Since it is hard to estimate precisely the IV coefficient on trade with telephone traffic, it would be interesting to see each estimated on its own. ${ }^{16}$ Table 3 reports the results. The instruments are their respective predicted components based on the gravity model and two measures of size, namely, area and population. For reference, the first two columns effectively reproduce the estimates reported by Frankel and Romer (1999), using only geographic variables to construct the instrument in the first stage. Columns (3) and (4) replicate the estimates by including linguistic and colonial variables in the first stage as well. This increases the IV estimate of the coefficient on trade slightly from 1.97 to 2.33 , which remains moderately statistically significant. The last two columns report the results when telephone traffic is estimated on its own without trade share. The IV estimate of the elasticity is 0.41 , which is statistically significant at the conventional levels.

Table 4 reports the OLS and the IV regressions that include both trade and telephone traffic. The full sample consists of all 106 countries for which data are available. All regressions control for two measures of size, namely, area and population. Column (1) is an OLS regression. It shows that trade shares enter insignificantly when telephone

${ }^{15}$ Throughout, the standard errors for the IV regressions are corrected to take into account the fact that the instruments are constructed from the bilateral equations and hence depend on the parameters of the bilateral equations. That is, the variance-covariance matrix of the coefficients is estimated as the usual IV formula plus $(\partial \hat{c} / \partial \hat{a}) \hat{\Omega}_{a a}(\partial \hat{c} / \partial \hat{a})^{\prime}+(\partial \hat{c} / \partial \hat{b}) \hat{\Omega}_{b b}(\partial \hat{c} / \partial \hat{b})^{\prime}$, where $\hat{a}$ and $\hat{b}$ are the coefficient vectors in the bilateral trade and telephone call traffic regressions respectively, $\hat{c}$ is the coefficient vector in the final income regression, $\hat{\Omega}_{a a}$ and $\hat{\Omega}_{b b}$ are the estimated variance-covariance matrice of $\hat{a}$ and $\hat{b}$ respectively. For more details on standard error adjustment when constructed regressors are used, see Paul A. Ruud (2000).

${ }^{16}$ I thank the anonymous referee for this suggestion. Obviously, even the IV estimates in these regressions are biased if both trade and telephone call traffic matter. But one might like to know the point estimate and precision of telephone traffic coefficient alone and see how close this paper comes to replicating the earlier result by Frankel and Romer (1999). 
call traffic is also included. The OLS estimate on trade share has a 95 percent confidence upper bound of 0.03 , which is virtually zero. On the contrary, the coefficient on telephone call traffic per worker is positive, and is economically and statistically significant. A one percent increase in the telephone call traffic per worker is associated with a 0.52 percent rise in income per worker.

Columns (2) and (3) are the IV regressions. They differ in how the instruments for trade shares and telephone call taffic per worker are constructed: column (2) constructs the instruments with only geographic and linguistic variables; column (3) includes the colonial variables in addition. Both yield quantitatively and qualitatively similar results: trade share is not statistically significant, while telephone call traffic is statistically significant at the conventional levels. ${ }^{17}$

How does the estimated effect of trade on income compare to Frankel and Romer (1999)? Frankel and Romer (1999) present a baseline IV estimate on trade share of 1.97, with a standard error of 0.99 for the 150-country sample. This implies that a one-percentage-point increase in trade share would raise income per worker by 2.0 percent. On the other hand, when the effect of telephone call traffic is controlled for, the baseline estimate in column (3) implies that the same increase in trade share would only advance income per worker by 0.5 percent, which is about a quarter of the magnitude found in Frankel and Romer (1999).

Which is the more important determinant of output per worker? To determine the relative importance of embodied versus disembodied idea flows, the "beta coefficients" are calculated by multiplying the coefficient estimate and the standard deviation of the corresponding explanatory variable, and dividing the product by the standard deviation of the dependent variable. The baseline estimates in column (3) imply a beta coefficient of $(0.47 \times 0.47 / 1.01=) 0.22$ for trade and $(0.38 \times 1.99 / 1.01=) 0.75$ for telephone call traffic per worker. This means that a one standard deviation increase in trade share would lead to a 0.22 standard deviation increase in the logarithm of output per worker. On the other hand, a one standard deviation increase in the logarithm of telephone call traffic per worker would explain a 0.75 standard deviation increase in the logarithm of output per worker. Clearly, telephone call traffic or disembodied idea flows are by far the more important force at work here.

Note that the effect of trade on income is not statistically significant in this paper, not because it is estimated less

${ }^{17}$ In results not shown here, if one follows Frankel and Romer and uses only geographic variables in the bilateral regressions, the instruments turn out not to be powerful enough to separate the effects of trade and communication on income: the model as a whole is not statistically significant; it has a model F-statistic equals 0.53 . 
precisely - in fact, it has a smaller standard error than Frankel and Romer's estimate - but because its point estimate becomes much smaller when the regression includes telephone call traffic. Thus, there appears to be relatively little support for the embodied object models when both trade and telephone call traffic are included in the regressions.

\subsection{Further Discussions}

La Porta et al. (1999) and Hall and Jones (1999) also employ various geographic, linguistic, and colonial variables to construct instruments in their empirical analyses: La Porta et al. (1999) use historical variables to investigate the effect of legal origins on variations in government performance across countries; Hall and Jones (1999) use geographic and linguistic variables to study whether "social infrastructure" causes cross-country income differences. ${ }^{18}$ These two papers can be related to my paper in two aspects.

First, the adoption of different legal systems and social infrastructure can be seen as specific examples of disembodied idea flows. Thus, this paper investigates how much disembodied idea flows in general explain cross-country income differences.

Second, although my paper also uses geographic, linguistic, and colonial variables, it differs from La Porta et al. (1999) and Hall and Jones (1999) in how the instruments are constructed: Frankel and Romer (1999) and I construct the instruments at the bilateral level; La Porta et al. (1999) and Hall and Jones (1999), however, do it at the aggregate level. Consequently, there is a fundamental difference in the types and forms of geographic, linguistic, and colonial variables used. All the geographic, linguistic, and colonial variables used in this paper are specific to the country pairs. Constructing the instruments at the bilateral level is preferable since it is even more difficult to imagine how these country-pair specific geographic, linguistic, and colonial variables could correlate with the error in the aggregate income regression.

\subsection{Robustness}

A natural question is whether the results are robust. I evaluate robustness along five dimensions.

The first concern is the possibility that the two outliers in the first stage trade regression - Luxembourg and Singapore - are driving the results. ${ }^{19}$ Table 5 reports the OLS and IV estimates when these two outliers are dropped ${ }^{18}$ Their measure of "social infrastructure" is essentially a measure of societal protection from appropriation.

${ }^{19} \mathrm{As}$ I argued earlier, this paper can be seen as an extension of the endogenous technological change model of 
from the income regression. Omitting the outliers generally raises the coefficient estimate on trade share and the standard errors of all estimates. All the IV estimates have the expected sign. The IV estimate on trade share more than doubles, although it is still not statistically significant. On the other hand, the IV estimate on telephone call traffic changes little, although it is no longer statistically significant. ${ }^{20}$

Second, if geography has an independent effect on income, for reasons unrelated to trade or communication, then the IV estimates based on instruments constructed from geographic factors may be biased. However, since the instruments are constructed at the bilateral level, it is hard to imagine how they may systematically capture any independent effect geography might have on income at the aggregate level. Nevertheless, two sets of geographic controls are used to check for robustness.

The first set of geographic controls includes three continent dummies: one for African countries, one for Latin American countries, and one for Asian countries. Columns (1) and (2) in Table 6 re-estimate the OLS and IV regressions including these continent dummies. Trade share is still not statistically significant; telephone call traffic, on the other hand, remains statistically significant with the correct sign. However, the results do not rule out the possibility that geographic factors may have an independent effect on income at the aggregate level: the African dummy is Kremer (1993) when idea diffusion is costly. Essentially, trade and telephone call traffic allow the individual country to overcome the limitations of its small size by providing channels through which individual country could tap into ideas generated elsewhere. Consequently, the relevant population for idea production for a given country is not only its domestic residents, but is effectively augmented by the extent of its interactions with the rest of the world through trade and telephone call traffic. Thus, unlike other papers on cross-country economic growth, small countries such as Luxembourg and Singapore should really be included in the sample, as they would benefit the most from embodied and disembodied idea flows from abroad. In the context of the model, they are not outliers, but are the very countries that the model seeks to explain.

${ }^{20}$ Note that in calculating the adjusted standard errors in this table, the bilateral regressions have been calculated using all available observations. The outliers are omitted only in the second stage. Had all calculations been performed excluding the outliers, the coefficient estimate on trade share in column (3) would have been 1.26 , with standard errors equal to 1.38. Similarly, under the alternative calculation, the coefficient estimate on telephone call traffic would have been 0.31 , with standard errors equal to 0.25 . 
negative and statistically significant; the Latin America dummy enters negatively and the Asian dummy positively, although both are not statistically significant.

The second geographic control is a country's distance from the equator. The OLS and IV estimates are reported in columns (3) and (4) in Table 6. Although the OLS estimates remain largely unchanged, the IV estimates become highly erratic: the standard errors of the estimates increase substantially; none of the coefficients remain statistically significant. However, given the large standard errors, one cannot reject the hypothesis that these coefficients are equal to the baseline estimates. Douglas A. Irwin and Marko Terviö (2001) encounter the same problem when they replicate Frankel and Romer's estimates using historical data on income and trade. They point out that since latitude does not have a natural economic interpretation, it is not clear what this result means. In particular, the mechanisms through which latitude might affect economic performance remain unclear.

Third, independent of trade and communication, countries populated by European emigrants and their descendants may simply have higher income. Columns (5) and (6) re-estimate the baseline regression including two measures of languages used in Hall and Jones (1999): the fraction of the population speaking English as the first language, and the fraction speaking English, French, Spanish, German, or Portuguese as the first language. The coefficients on trade share and telephone call traffic per worker change little, although they have each become statistically insignificant. However, the test for the joint significance of trade and telephone call traffic yields an F-statistic of 5.00, which is statistically significant. Neither of the linguistic measures are individually or jointly significant; the test for joint significance of the linguistic variables yields an F-statistic of 0.43 .

Fourth, I consider the possibility that colonial heritage may have an independent effect on income, for reasons unrelated to trade or telephone call traffic. To investigate this possibility, I include three colonial dummies in the income regression for ex-colonies of Great Britain, France, and Spain. Columns (7) and (8) report the OLS and IV estimates. The effect of trade share is small and not statistically significant at the conventional levels. Telephone call traffic continues to have an economically large and statistically significant impact on income. The french colonial dummy is negative and statistically significant. However, given the results on the continent dummies, one cannot distinguish whether this reflects the effect of french colonial heritage or the effect of other omitted variables that had most severely affected the African continent.

Finally, I investigate robustness with respect to functional form. To facilitate comparison with the results in Frankel 
and Romer (1999), I have chosen a logarithmic specification for telephone traffic but a linear specification for trade in the income regression. ${ }^{21}$ One might object to the asymmetric specification of trade and telephone traffic. Thus, Table 7 reports the OLS and IV estimates if both trade share and telephone call traffic enter symmetrically in linear and logarithmic forms.

Columns (1) and (2) report the OLS and IV estimates when both trade share and telephone call traffic enter linearly. The IV estimates in column (2) show that the coefficient on trade share has the wrong sign. However, given the large standard error, the point estimate is uninformative. On the other hand, telephone call traffic per worker has a beta coefficient of $(0.0056 \times 67.84 / 1.01=) 0.38$. In other words, a one standard deviation increase in telephone call traffic per worker would explain a 0.38 standard deviation increase in the logarithm of output per worker. However, the estimate is also statistically insignificant at the conventional levels.

Finally, columns (3) and (4) show the estimates using the logarithmic specification. The IV estimates in column (4) imply an elasticity of output per worker with respect to trade share of 0.64 and an elasticity with respect to telephone call traffic per worker of 0.32 . However, since trade share varies much less than telephone traffic per worker, these elasticity estimates do not reveal the quantitative impact of each variable. In fact, these elasticity estimates imply a beta coefficient of $(0.64 \times 0.62 / 1.01=) 0.39$ for the logarithm of trade share and a beta coefficient of $(0.32 \times 1.99 / 1.01=)$ 0.63 for the logarithm of telephone call traffic per worker. In other words, a one standard deviation increase in the logarithm of trade share would lead to a 0.39 standard deviation increase in the logarithm of output per worker. On the other hand, a one standard deviation increase in the logarithm of telephone call traffic per worker would explain a 0.63 standard deviation increase in the logarithm of output per worker. Telephone call traffic is still the more important determinant of output per worker.

${ }^{21}$ Trade share enters linearly in Frankel and Romer (1999). However, they report that their conclusions are unaffected by using the logarithm of trade share instead of the level. 


\section{The Channels Through Which Trade and Telephone Call Traffic Affect Income: Idea Gaps Versus Object Gaps}

Following the lead of Frankel and Romer (1999), this section investigates the channels through which trade and telephone call traffic affect income using a two-step channel accounting exercise: first, following Hall and Jones (1999), income per worker is decomposed into three components, i.e., contributions from physical capital per worker, human capital per worker, and total factor productivity:

$$
\ln \left(Y_{i} / L_{i}\right)=\frac{\alpha}{1-\alpha} \ln \left(K_{i} / Y_{i}\right)+\ln \left(H_{i} / L_{i}\right)+\ln A_{i}
$$

where $\alpha$ is set to $1 / 3, Y$ is income, $L$ is labor, $K$ is physical capital, $H$ is human capital, and $A$ is total factor productivity; next, each component of income is regressed on trade and telephone call traffic, controlling for population and area. ${ }^{22}$

Table 8 reports the OLS and IV estimates from the channel accounting exercise. The IV estimates reveal that trade affects income mainly through aggregate factor accumulation, although none of the individual channels are statistically significant. In contrast, communication advances income predominantly through total factor productivity, although the estimate is barely statistically significant at the ten percent level. Telephone call traffic has virtually no effect on aggregate factor accumulation. The last row in Table 8 reports the test statistics for the joint significance of trade share and telephone call traffic per worker. Based on these statistics, the hypothesis that trade share and telephone call traffic have no effect on TFP can be rejected. However, there is little evidence that trade share and telephone call traffic per worker have a jointly significant effect on physical capital and human capital accumulation. Summarizing, it appears that it is disembodied idea flows, not embodied idea flows, that help bridge income gaps; furthermore, these flows operate through idea gaps, not object gaps.

\section{Conclusion}

This paper empirically distinguishes between the relative importance of embodied versus disembodied idea flows in closing income gaps and TFP gaps. Specifically, I use trade share and telephone call traffic per worker as proxies for

\footnotetext{
${ }^{22}$ For more details on the methodology and interpretation of channel accounting, see Wei-Kang Wong (2001).
} 
embodied and disembodied idea flows respectively. However, since trade and telephone call traffic are likely to be endogenous, to identify their effects on income, they have to be instrumented.

To construct the instruments, I first predict the bilateral trade share and telephone call traffic per worker based on the country-pair specific geographic, linguistic, and colonial characteristics. I then aggregate these predicted values to derive the instruments - the geographic, linguistic, and colonial components of countries' overall trade and telephone call traffic abroad. The results suggest that linguistic similarity is a crucial determinant of cross-border interactions. Because the same exogenous variables explain both trade and telephone call traffic, to use these variables to identify trade's effect on income, the regression needs to control for telephone call traffic, and vice versa; otherwise, the estimates would be biased.

The IV estimates obtained with these instruments suggest that telephone call traffic has an economically larger effect on income per worker than trade. Furthermore, trade's effect on income is reduced greatly when the telephone call traffic is controlled for. The effect of telephone call traffic seems to work through total factor productivity rather than aggregate factor accumulation. Thus, telephone call traffic, not trade, emerges as the main channel of technology transfer. There is relatively little empirical support for the embodied object models when measures of both embodied and disembodied idea flows are included in the regressions.

The estimated impact of telephone call traffic on cross-country income has some stability across different specifications. However, the results are sensitive to the inclusion of the latitude variable: the latitude variable raises the standard errors of all estimates substantially; none of the variables remain statistically significant, from zero or from the baseline estimates.

At the very least, these results raise doubt in the precision of the estimated effect of trade on income derived from the gravity model, regardless of my interpretations of trade and telephone call traffic as embodied and disembodied idea flows respectively. Given the wide acceptance of these estimates, any reasonable doubt in the estimates should at least be noted. For example, Frankel and Rose (2002) use these estimates to calculate the effect of common currencies on income via trade. If the effect of trade on income becomes much smaller when previously omitted variable is included, as the results in this paper indicate, then the effect of common currencies on income via trade could turn out to be much smaller than previously thought. 


\section{References}

[1] Borensztein, E., De Gregorio, J, Lee, J.W., 1998. How Does Foreign Direct Investment Affect Economic Growth? Journal of International Economics 45, 115-135.

[2] Central Intelligence Agency, 2000. The World Factbook. http://www.cia.gov/cia/publications/factbook/index.html

[3] Coe, D.T., Helpman, E., 1995. International R\&D Spillover. European Economic Review 39, 859-887.

[4] Coe, D.T., Helpman, E., Hoffmaister, A.W., 1997. North-South R \& D Spillovers. Economic Journal 107, $134-$ 149.

[5] De Long, J.B., Summers, L.H., 1991. Equipment Investment. Quarterly Journal of Economics 106, 445-502.

[6] Frankel, J.A., Romer, D., 1999. Does Trade Cause Growth? American Economic Review 89, 379-399.

[7] Frankel, J., Rose, A., 2002. An Estimate of the Effect of Common Currencies on Trade and Income. Quarterly Journal of Economics 117, 437-466.

[8] Hall, R.E., Jones, C.I., 1999. Why Do Some Countries Produce So Much More Output Per Worker than Others? Quarterly Journal of Economics 114, 83-116.

[9] Hercowitz, Z., 1998. The 'Embodiment' Controversy: A Review Essay. Journal of Monetary Economics 41, 217-224.

[10] International Telecommunications Union, 1996. Direction of Traffic - Trends in International Telephone Tariffs. Geneva.

[11] International Telecommunications Union 1995. World Telecommunication Indicators. Geneva.

[12] Irwin, D.A., Terviö, M., 2001. Does Trade Raise Income? Evidence from the Twentieth Century. Mimeo.

[13] Jorgenson, D.W., 1966. The Embodiment Hypothesis. Journal of Political Economy 74, 1-17.

[14] Kremer, M., 1993. Population Growth and Technological Change: One Million B.C. to 1990. Quarterly Journal of Economics 108, 681-716. 
[15] La Porta, R., Lopez-de-Silanes, F., Shleifer, A., Vishny, R., 1999. The Quality of Government. Journal of Law, Economics, and Organization 15, 222-279.

[16] Mokyr, J., 1990. The Lever of Riches. Oxford University Press, New York.

[17] Portes, R., Rey, H., 2000. The Determinants of Cross-Border Equity Flows: The Geography of Information. Mimeo.

[18] Rodriguez, F., Rodrik, D., 2000. Trade Policy and Economic Growth: A Skeptic's Guide to Cross-National Evidence. Mimeo.

[19] Romer, P., 1990. Endogenous Technological Change. Journal of Political Economy 98, S71-S102.

[20] Romer, P., 1993. Idea Gaps and Object Gaps in Economic Development. Journal of Monetary Economics 32, $543-573$.

[21] Solow, R.M., Investment and Technical Progress, in: Arrow, K.J., Karlin, S., Suppes, P. (Eds.), Mathematical Methods in the Social Sciences. Stanford University Press, Stanford, pp. 89-104.

[22] Summer Institute of Linguistics, various years. Ethnologue: Languagues of the World. Dallas, Texas. http://www.ethnologue.com/web.asp

[23] Wong, W.K., 2002. Economic Growth: A Channel Accounting Exercise. Mimeo. 
Table 1: Determinants of Trade and Telephone Call Traffic

\begin{tabular}{|c|c|c|}
\hline \multirow[b]{2}{*}{ Regressors } & \multicolumn{2}{|c|}{ Dependent Variable } \\
\hline & $\operatorname{lnTe} l_{i j}$ & $\operatorname{lnTrade}_{i j}$ \\
\hline \multirow[t]{2}{*}{ constant } & 8.48 & -6.41 \\
\hline & $(0.53)$ & $(0.41)$ \\
\hline \multirow[t]{2}{*}{ ln (Distance) } & -1.38 & -0.84 \\
\hline & $(0.06)$ & $(0.03)$ \\
\hline \multirow[t]{2}{*}{$\ln ($ Population in Country $i$ ) } & -0.32 & -0.24 \\
\hline & $(0.04)$ & $(0.03)$ \\
\hline \multirow[t]{2}{*}{$\ln ($ Area in Country $i$ ) } & -0.22 & -0.13 \\
\hline & $(0.03)$ & $(0.02)$ \\
\hline \multirow[t]{2}{*}{$\ln ($ Population in Country $j$ ) } & 0.70 & 0.61 \\
\hline & $(0.04)$ & $(0.03)$ \\
\hline \multirow[t]{2}{*}{$\ln ($ Area in Country $j)$} & -0.13 & -0.19 \\
\hline & $(0.03)$ & $(0.02)$ \\
\hline \multirow[t]{2}{*}{ Landlocked Dummy } & -1.20 & -0.32 \\
\hline & $(0.12)$ & $(0.07)$ \\
\hline \multirow[t]{2}{*}{ Common Border Dummy } & 6.82 & 4.31 \\
\hline & $(2.29)$ & $(2.24)$ \\
\hline \multirow[t]{2}{*}{ Common Border Dummy * $\ln ($ Distance) } & -0.35 & 0.26 \\
\hline & $(0.37)$ & $(0.38)$ \\
\hline \multirow[t]{2}{*}{ Common Border Dummy $* \ln ($ Population in $i$ ) } & -0.60 & -0.28 \\
\hline & $(0.24)$ & $(0.21)$ \\
\hline \multirow[t]{2}{*}{ Common Border Dummy $* \ln ($ Area in $i)$} & 0.26 & -0.07 \\
\hline & $(0.22)$ & $(0.18)$ \\
\hline \multirow[t]{2}{*}{ Common Border Dummy * $\ln ($ Population in $j$ ) } & -0.20 & -0.11 \\
\hline & $(0.20)$ & $(0.22)$ \\
\hline \multirow[t]{2}{*}{ Common Border Dummy $* \ln ($ Area in $j)$} & -0.03 & -0.09 \\
\hline & $(0.18)$ & $(0.19)$ \\
\hline \multirow[t]{2}{*}{ Common Border Dummy * Landlocked Dummy } & 1.65 & 0.37 \\
\hline & $(0.34)$ & $(0.22)$ \\
\hline \multirow[t]{2}{*}{ Prob ( $i$ and $j$ Speak the Same Language) } & 1.69 & 0.93 \\
\hline & $(0.26)$ & $(0.23)$ \\
\hline \multirow[t]{2}{*}{ Dummy for Britain and its ex-colonies } & 3.67 & 1.59 \\
\hline & $(0.29)$ & $(0.18)$ \\
\hline \multirow[t]{2}{*}{ Dummy for France and its ex-colonies } & 3.64 & 1.81 \\
\hline & $(0.13)$ & $(0.40)$ \\
\hline \multirow[t]{2}{*}{ Dummy for Spain and its ex-colonies } & 1.50 & 0.30 \\
\hline & $(0.38)$ & $(0.27)$ \\
\hline$R^{2}$ & 0.43 & 0.37 \\
\hline Sample Size & 3052 & 3220 \\
\hline
\end{tabular}

Note: Heteroskedasticity-consistent standard errors are in parentheses. 
Table 2: The Relations Between Actual and Constructed Trade and Telephone Traffic

\begin{tabular}{|c|c|c|c|c|}
\hline \multirow[b]{2}{*}{ Regressors } & \multicolumn{4}{|c|}{ Dependent Variable } \\
\hline & $\operatorname{lnTel_{i}}$ & Trade $_{i}$ & $\operatorname{lnTel_{i}}$ & Trade $_{i}$ \\
\hline & \multicolumn{2}{|c|}{ Entire Sample } & \multicolumn{2}{|c|}{ Outliers Omitted } \\
\hline \multirow[t]{2}{*}{ constant } & 1.83 & 1.62 & 1.60 & 1.35 \\
\hline & (1.78) & $(0.27)$ & $(2.05)$ & $(0.25)$ \\
\hline \multirow{2}{*}{ lnPopulation $_{i}$} & -0.09 & -0.05 & -0.11 & -0.06 \\
\hline & $(0.14)$ & $(0.02)$ & $(0.15)$ & $(0.02)$ \\
\hline \multirow[t]{2}{*}{$\operatorname{lnArea}_{i}$} & -0.03 & -0.06 & 0.01 & -0.03 \\
\hline & $(0.12)$ & $(0.02)$ & $(0.14)$ & $(0.02)$ \\
\hline \multirow[t]{2}{*}{ Trade $_{i}$} & 0.93 & 0.51 & 0.88 & 0.64 \\
\hline & $(0.92)$ & $(0.16)$ & (1.77) & $(0.25)$ \\
\hline \multirow[t]{2}{*}{$\ln \widehat{T e} l_{i}$} & 0.41 & -0.004 & 0.42 & -0.005 \\
\hline & $(0.23)$ & $(0.04)$ & $(0.25)$ & $(0.03)$ \\
\hline$R^{2}$ & 0.27 & 0.52 & 0.23 & 0.54 \\
\hline Adj. $R^{2}$ & 0.24 & 0.51 & 0.20 & 0.52 \\
\hline Sample Size & 106 & 150 & 104 & 148 \\
\hline First Stage F Statistic ${ }^{a}$ & 4.12 & 6.58 & 3.07 & 5.03 \\
\hline
\end{tabular}

Note: Standard errors are in parentheses.

${ }^{a}$ The hypothesis is that the coefficients on constructed trade share and telephone call traffic are jointly zero. 
Table 3: Trade and Income versus Telephone Traffic and Income

\begin{tabular}{lcccccc}
\hline \multicolumn{7}{c}{ Dependent Variable: $\ln (\mathrm{GDP}$ per } \\
\hline Regressors & $(1)$ & $(2)$ & $(3)$ & $(4)$ & $(5)$ & $(6)$ \\
& OLS & IV $^{F R}$ & OLS & IV & OLS & IV \\
\hline constant & 7.40 & 5.07 & 7.40 & 4.16 & 6.36 & 6.96 \\
& $(0.66)$ & $(2.18)$ & $(0.66)$ & $(2.39)$ & $(0.27)$ & $(0.77)$ \\
$\ln$ (Population) & 0.12 & 0.19 & 0.12 & 0.22 & 0.16 & 0.14 \\
& $(0.06)$ & $(0.09)$ & $(0.06)$ & $(0.10)$ & $(0.03)$ & $(0.05)$ \\
$\ln$ (Area) & -0.01 & 0.08 & -0.01 & 0.12 & 0.03 & 0.01 \\
& $(0.06)$ & $(0.10)$ & $(0.06)$ & $(0.11)$ & $(0.03)$ & $(0.04)$ \\
Trade Share & 0.85 & 1.92 & 0.85 & 2.33 & & \\
& $(0.25)$ & $(0.98)$ & $(0.25)$ & $(1.07)$ & & \\
$\ln$ (Telephone Traffic per Worker) & & & & & 0.51 & 0.41 \\
& & & & & $(0.03)$ & $(0.12)$ \\
\hline$R^{2}$ & 0.09 & 0.09 & 0.09 & - & 0.80 & 0.77 \\
Sample Size & 150 & 150 & 150 & 150 & 106 & 106 \\
\hline
\end{tabular}

Note: Standard errors are in parentheses.

$F R$ The instruments are constructed using only the geographic variables. 
Table 4: Trade, Telephone Call Traffic, and Income (Full Sample)

\begin{tabular}{lccc}
\hline \multicolumn{4}{c}{ Dependent Variable: In (GDP per worker at 1985) } \\
\hline Regressors & $(1)$ & $(2)$ & $(3)$ \\
& OLS & $I V^{m}$ & $I V^{l}$ \\
\hline constant & 6.83 & 6.40 & 6.09 \\
& $(0.38)$ & $(1.32)$ & $(1.43)$ \\
$\ln$ (Population) & 0.16 & 0.14 & 0.14 \\
& $(0.03)$ & $(0.05)$ & $(0.05)$ \\
$\ln$ (Area) & 0.01 & 0.05 & 0.07 \\
& $(0.03)$ & $(0.09)$ & $(0.09)$ \\
Trade Share & -0.25 & 0.27 & 0.47 \\
& $(0.14)$ & $(0.87)$ & $(0.86)$ \\
$\ln$ (Telephone Traffic per Worker) & 0.52 & 0.40 & 0.38 \\
& $(0.03)$ & $(0.20)$ & $(0.17)$ \\
\hline$R^{2}$ & 0.81 & 0.76 & 0.73 \\
Sample Size & 106 & 106 & 106 \\
\hline
\end{tabular}

Note: Standard errors are in parentheses.

$m$ The instruments are constructed using the geographic and linguistic variables.

${ }^{l}$ The instruments are constructed using the geographic, linguistic, and colonial variables. 
Table 5: Trade, Telephone Call Traffic, and Income (Outliers Omitted)

\begin{tabular}{lccc}
\hline \multicolumn{4}{c}{ Dependent Variable: ln (GDP per worker at 1985) } \\
\hline Regressors & $(1)$ & $(2)$ & $(3)$ \\
& OLS & $I V^{m}$ & $I V^{l}$ \\
\hline constant & 6.93 & 5.42 & 4.98 \\
& $(0.41)$ & $(2.10)$ & $(2.21)$ \\
$\ln$ (Population) & 0.15 & 0.18 & 0.18 \\
& $(0.04)$ & $(0.07)$ & $(0.07)$ \\
$\ln$ (Area) & 0.01 & 0.08 & 0.11 \\
& $(0.03)$ & $(0.10)$ & $(0.11)$ \\
Trade Share & -0.32 & 0.77 & 1.21 \\
& $(0.18)$ & $(1.38)$ & $(1.41)$ \\
$\ln$ (Telephone Traffic per Worker) & 0.53 & 0.41 & 0.33 \\
& $(0.03)$ & $(0.23)$ & $(0.23)$ \\
\hline$R^{2}$ & 0.80 & 0.72 & 0.61 \\
Sample Size & 104 & 104 & 104 \\
\hline
\end{tabular}

Note: Standard errors are in parentheses.

${ }^{m}$ The instruments are constructed using the geographic and linguistic variables.

${ }^{l}$ The instruments are constructed using the geographic, linguistic, and colonial variables. 
Table 6: Trade, Telephone Call Traffic, and Income - Robustness Checks

\begin{tabular}{|c|c|c|c|c|c|c|c|c|}
\hline \multirow{3}{*}{ Regressors } & \multicolumn{8}{|c|}{ Dependent Variable: $\ln ($ GDP per worker at 1985) } \\
\hline & (1) & $(2)$ & (3) & $(4)$ & $(5)$ & $(6)$ & $(7)$ & $(8)$ \\
\hline & OLS & IV & OLS & IV & OLS & IV & OLS & IV \\
\hline \multirow[t]{2}{*}{ constant } & 7.44 & 7.41 & 6.89 & 8.37 & 6.83 & 5.99 & 7.04 & 6.75 \\
\hline & $(0.31)$ & $(1.07)$ & $(0.38)$ & $(3.77)$ & $(0.39)$ & $(1.59)$ & $(0.40)$ & $(1.14)$ \\
\hline \multirow[t]{2}{*}{$\ln$ (Population) } & 0.06 & 0.06 & 0.13 & -0.11 & 0.16 & 0.14 & 0.12 & 0.11 \\
\hline & $(0.03)$ & $(0.05)$ & $(0.04)$ & $(0.43)$ & $(0.03)$ & $(0.05)$ & $(0.04)$ & $(0.05)$ \\
\hline \multirow[t]{2}{*}{$\ln ($ Area $)$} & 0.05 & 0.05 & 0.01 & 0.02 & 0.01 & 0.07 & 0.03 & 0.06 \\
\hline & $(0.02)$ & $(0.05)$ & $(0.03)$ & $(0.15)$ & $(0.03)$ & $(0.10)$ & $(0.03)$ & $(0.07)$ \\
\hline \multirow[t]{2}{*}{ Trade Share } & -0.25 & -0.22 & -0.22 & 0.46 & -0.24 & 0.61 & -0.21 & 0.06 \\
\hline & $(0.11)$ & $(0.42)$ & $(0.14)$ & $(1.60)$ & $(0.15)$ & $(1.04)$ & $(0.14)$ & $(0.65)$ \\
\hline \multirow[t]{2}{*}{ ln (Telephone Traffic/Worker) } & 0.45 & 0.45 & 0.48 & -0.11 & 0.52 & 0.32 & 0.49 & 0.45 \\
\hline & $(0.03)$ & $(0.11)$ & $(0.03)$ & (1.04) & $(0.03)$ & $(0.23)$ & $(0.03)$ & $(0.11)$ \\
\hline \multirow[t]{2}{*}{ African Dummy } & -0.66 & -0.67 & & & & & & \\
\hline & $(0.11)$ & $(0.30)$ & & & & & & \\
\hline \multirow[t]{2}{*}{ Latin America Dummy } & -0.13 & -0.14 & & & & & & \\
\hline & $(0.10)$ & $(0.18)$ & & & & & & \\
\hline \multirow[t]{2}{*}{ Asian Dummy } & 0.31 & 0.30 & & & & & & \\
\hline & $(0.11)$ & $(0.21)$ & & & & & & \\
\hline \multirow[t]{2}{*}{ Distance from Equator } & & & 0.62 & 3.96 & & & & \\
\hline & & & $(0.31)$ & $(5.96)$ & & & & \\
\hline \multirow[t]{2}{*}{ English } & & & & & 0.07 & 0.09 & & \\
\hline & & & & & $(0.21)$ & $(0.30)$ & & \\
\hline \multicolumn{2}{|l|}{ English, French, German, } & & & & 0.01 & 0.37 & & \\
\hline \multicolumn{2}{|l|}{ Spanish, or Portuguese } & & & & $(0.14)$ & $(0.44)$ & & \\
\hline \multirow[t]{2}{*}{ British Colony } & & & & & & & -0.09 & -0.14 \\
\hline & & & & & & & $(0.11)$ & $(0.16)$ \\
\hline \multirow[t]{2}{*}{ French Colony } & & & & & & & -0.45 & -0.53 \\
\hline & & & & & & & $(0.15)$ & $(0.25)$ \\
\hline \multirow[t]{2}{*}{ Spanish Colony } & & & & & & & -0.10 & -0.07 \\
\hline & & & & & & & $(0.14)$ & $(0.18)$ \\
\hline$R^{2}$ & 0.90 & 0.90 & 0.81 & 0.21 & 0.81 & 0.70 & 0.82 & 0.81 \\
\hline Sample Size & 106 & 106 & 106 & 106 & 106 & 106 & 106 & 106 \\
\hline
\end{tabular}

Note: Standard errors are in parentheses. 
Table 7: Trade, Telephone Call Traffic, and Income (Symmetric Linear and Logarithmic Forms)

\begin{tabular}{|c|c|c|c|c|}
\hline \multicolumn{5}{|c|}{ Dependent Variable: $\ln ($ GDP per worker at 1985) } \\
\hline \multirow[t]{2}{*}{ Regressors } & $(1)$ & $(2)$ & (3) & (4) \\
\hline & OLS & IV & OLS & IV \\
\hline \multirow[t]{2}{*}{ constant } & 7.89 & 9.41 & 6.69 & 6.49 \\
\hline & $(0.73)$ & $(8.89)$ & $(0.28)$ & $(1.18)$ \\
\hline \multirow[t]{2}{*}{$\ln$ (Population) } & 0.07 & 0.05 & 0.14 & 0.18 \\
\hline & $(0.07)$ & $(0.10)$ & $(0.03)$ & $(0.11)$ \\
\hline \multirow[t]{2}{*}{$\ln ($ Area $)$} & 0.02 & -0.06 & -0.002 & 0.08 \\
\hline & $(0.06)$ & $(0.50)$ & $(0.03)$ & $(0.18)$ \\
\hline \multirow[t]{2}{*}{ ln (Trade Share) } & & & -0.36 & 0.64 \\
\hline & & & $(0.11)$ & $(2.00)$ \\
\hline \multirow[t]{2}{*}{ In (Telephone Traffic per Worker) } & & & 0.54 & 0.32 \\
\hline & & & $(0.03)$ & $(0.39)$ \\
\hline \multirow[t]{2}{*}{ Trade Share } & 0.22 & -0.31 & & \\
\hline & $(0.28)$ & $(4.55)$ & & \\
\hline \multirow[t]{2}{*}{ Telephone Traffic per Worker } & 0.0075 & 0.0056 & & \\
\hline & $(0.0015)$ & $(0.011)$ & & \\
\hline$R^{2}$ & 0.26 & 0.20 & 0.82 & 0.63 \\
\hline Sample Size & 106 & 106 & 106 & 106 \\
\hline
\end{tabular}

Note: Standard errors are in parentheses. 
Table 8: The Channels Through Which Trade and Telephone Call Traffic Affect Income

\begin{tabular}{|c|c|c|c|c|c|c|}
\hline & \multicolumn{6}{|c|}{ Dependent Variable } \\
\hline & \multicolumn{2}{|c|}{$\frac{\alpha}{1-\alpha} \ln \left(K_{i} / Y_{i}\right)$} & \multicolumn{2}{|c|}{$\ln \left(H_{i} / L_{i}\right)$} & \multicolumn{2}{|c|}{$\underline{\ln \left(A_{i}\right)}$} \\
\hline & $(1)$ & $(2)$ & $(3)$ & (4) & $(5)$ & (6) \\
\hline & OLS & IV & OLS & IV & OLS & IV \\
\hline \multirow[t]{2}{*}{ constant } & -0.44 & -1.02 & -0.02 & -0.53 & 7.15 & 6.52 \\
\hline & $(0.20)$ & $(0.89)$ & $(0.19)$ & $(0.79)$ & $(0.42)$ & $(1.39)$ \\
\hline \multirow[t]{2}{*}{$\ln$ (Population) } & 0.05 & 0.03 & 0.08 & 0.07 & 0.12 & 0.11 \\
\hline & $(0.02)$ & $(0.03)$ & $(0.02)$ & $(0.03)$ & $(0.04)$ & $(0.05)$ \\
\hline \multirow[t]{2}{*}{$\ln$ (Area) } & 0.01 & 0.07 & -0.02 & 0.03 & -0.05 & -0.003 \\
\hline & $(0.02)$ & $(0.06)$ & $(0.02)$ & $(0.06)$ & $(0.04)$ & $(0.10)$ \\
\hline \multirow[t]{2}{*}{ Trade Share } & 0.003 & 0.53 & -0.05 & 0.41 & -0.22 & 0.19 \\
\hline & $(0.072)$ & $(0.50)$ & $(0.07)$ & $(0.46)$ & $(0.15)$ & $(0.83)$ \\
\hline \multirow{2}{*}{$\begin{array}{l}\text { In (Telephone Traffic } \\
\text { per worker) }\end{array}$} & 0.11 & -0.002 & 0.12 & 0.03 & 0.32 & 0.27 \\
\hline & $(0.01)$ & $(0.09)$ & $(0.01)$ & $(0.09)$ & $(0.03)$ & $(0.16)$ \\
\hline$R^{2}$ & 0.44 & - & 0.56 & 0.16 & 0.59 & 0.56 \\
\hline Sample Size & 91 & 91 & 91 & 91 & 91 & 91 \\
\hline SE of regression & 0.21 & 0.30 & 0.20 & 0.27 & 0.45 & 0.47 \\
\hline F-statistic $^{a}$ & - & 1.07 & - & 1.39 & - & 3.95 \\
\hline
\end{tabular}

Note: Standard errors are in parentheses.

${ }^{a}$ The hypothesis is that the coefficients on trade share and ln (telephone call traffic per worker) are jointly zero. 
Figure 1: Partial Correlation Between Actual and Constructed Trade Share Using All Available Observations

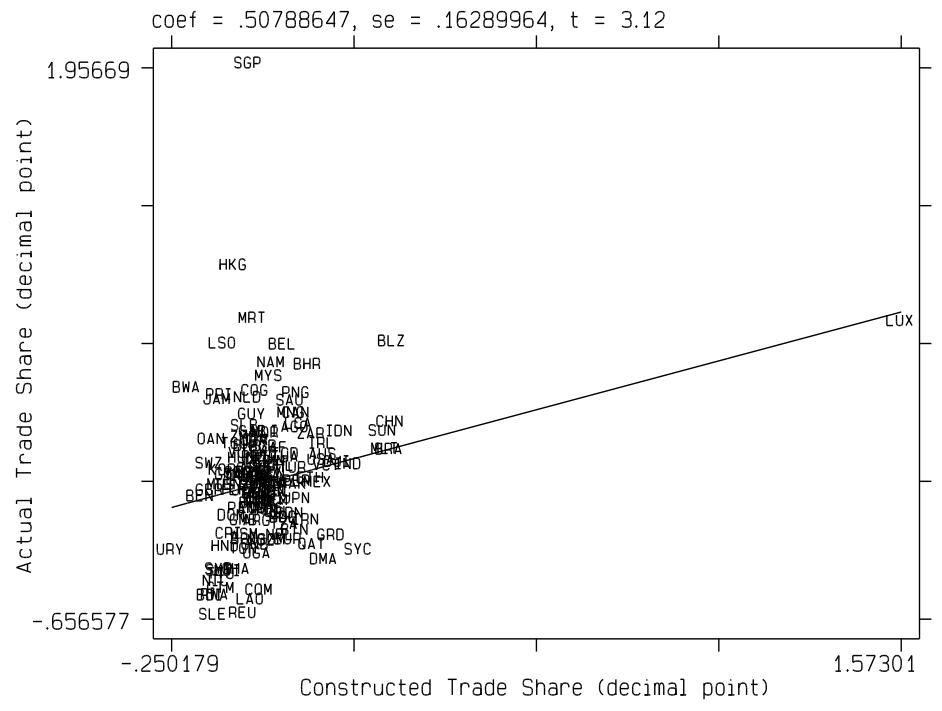


Figure 2: Partial Correlation Between Actual and Constructed Telephone Call Traffic Using All Available Observations

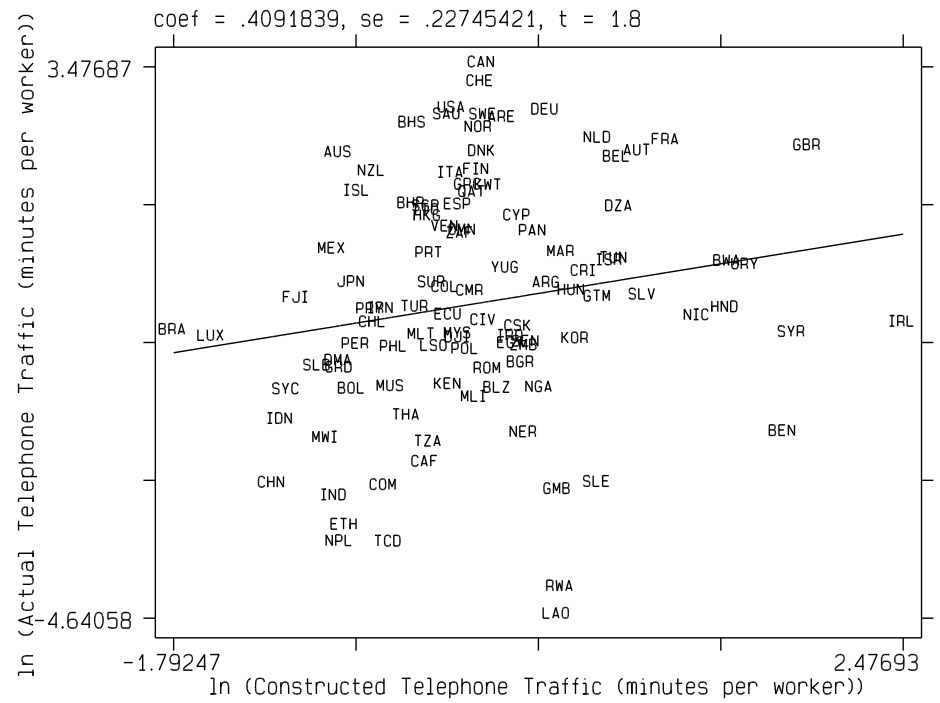


Figure 3: Partial Correlation Between Actual and Constructed Trade Share with Outliers Omitted

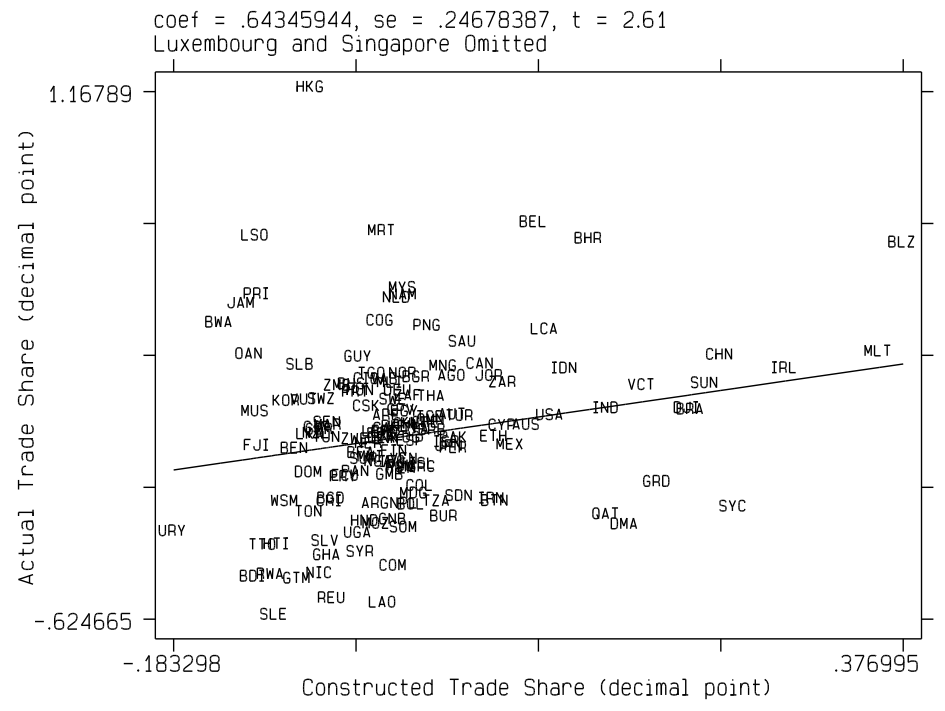


Figure 4: Partial Correlation Between Actual and Constructed Telephone Call Traffic with Outliers Omitted

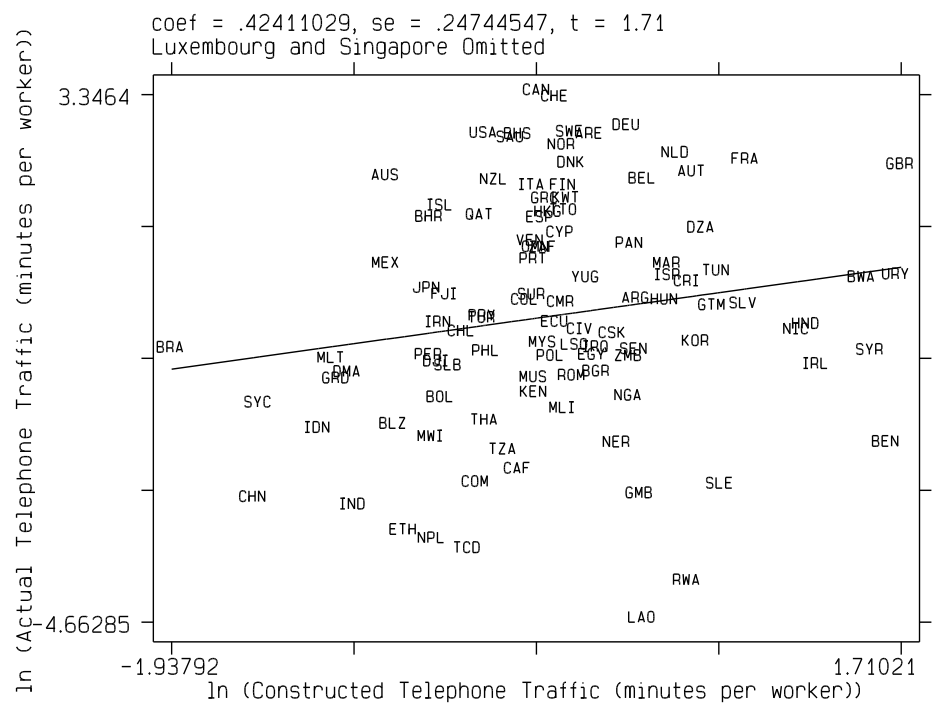

